\title{
Microstructure and Mechanical Properties of Mg-7.4\% Al Alloy Matrix Composites Reinforced by Nanocrystalline Al-Ca Intermetallic Particles
}

\author{
A. K. Chaubey $\cdot$ B. B. Jha $\cdot$ B. K. Mishra
}

Received: 21 July 2014/Revised: 27 August 2014/Published online: 4 February 2015

(c) The Chinese Society for Metals and Springer-Verlag Berlin Heidelberg 2015

\begin{abstract}
Mg}-7.6 \% \mathrm{Al}$ (in mass fraction) alloy matrix composites reinforced with different volume fractions of nanocrystalline $\mathrm{Al}_{3} \mathrm{Ca}_{8}$ particles were synthesized by powder metallurgy, and the effect of the volume fraction of reinforcement on the mechanical properties was studied. Room temperature compression test reveals considerable improvement on mechanical properties as compared to unreinforced matrix. The compressive strength increases from $683 \mathrm{MPa}$ for unreinforced alloy matrix to about 767 and $823 \mathrm{MPa}$ for the samples having 20 and $40 \mathrm{vol} \%$ of reinforcement, respectively, while retaining appreciable plastic deformation ranging between 12 and $24 \%$. The specific strength of the composites increased significantly, demonstrating the effectiveness of the low-density $\mathrm{Al}_{3} \mathrm{Ca}_{8}$ reinforcement.
\end{abstract}

KEY WORDS: Intermetallics; Consolidation; Dispersion strengthening; Powder metallurgy; Mechanical property; Electron microscopy

\section{Introduction}

In recent, past magnesium-based metal matrix composites (MMCs) are being used in automotive, electronics, and aerospace industries due to their low density, high specific strength, and excellent machinability [1-3]. MMCs reinforced with ceramic particles have extensively been used for several light weight and wear resistance applications [2-4]. However, owing to the high abrasiveness, brittleness, and wettability of ceramics [4-7] in recent years, intermetallics as reinforcements in MMCs have emerged as possible substitutes for ceramic reinforcements [8-11]. This appears to be a highly promising option in view of high hardness of intermetallics and their compatibility with the metal matrix. In addition, thermal expansion coefficients of intermetallics

Available online at http://link.springer.com/journal/40195

A. K. Chaubey $(\bowtie) \cdot$ B. B. Jha · B. K. Mishra

Institute of Minerals and Materials Technology (IMMT),

Bhubaneswar 751013, India

e-mail: anil.immt@gmail.com are much closer to the metals than those of ceramic reinforcements.

Among the intermetallics, $\mathrm{Al}_{3} \mathrm{Ca}_{8}$ (triclinic) and $\mathrm{Al}_{14} \mathrm{Ca}_{13}$ (monoclinic) [12] intermetallic phases of $\mathrm{Al}-\mathrm{Ca}$ system appear as a promising candidates for the use as reinforcing agent due to their extremely low densities (1.859 and $2.013 \mathrm{~g} / \mathrm{cm}^{3}$, respectively). $\mathrm{Al}_{3} \mathrm{Ca}_{8}$ is one of the important intermetallic phases in the $\mathrm{Al}-\mathrm{Ca}$ system that has excellent mechanical properties. It is well known that the mechanical properties of intermetallics are closely related to their structures and stability [13]. $\mathrm{Al}_{3} \mathrm{Ca}_{8}$ phase is known to be hard, brittle, and stable up to a temperature of $852 \mathrm{~K}$ [14] making it the most suitable candidate for reinforcement.

For most of the engineering applications, bulk sample is the prerequisite for the performance evaluation [15]. The key challenge in the processing of bulk composite samples is to get homogenous distribution of the reinforcing phases in order to achieve a uniform microstructure. The mechanical properties of an MMCS are strongly dependent on the properties of reinforcements, distribution, size, morphology and volume fraction of the reinforcement, as well as the interfacial strength between the reinforcement, 
and the matrix [16]. Due to their high surface area, nanosize powders will naturally tend to agglomerate in order to reduce their overall surface energy,hence making it difficult to obtain an uniform dispersion by most conventional liquid processing methods. Uniform distribution of reinforcement could be obtained by solid state processing methods. Powder metallurgy is one of solid state processing techniques and is highly flexible and versatile technique for producing metal matrix composites. An important advantage of this method is its low processing temperature compared to melting techniques. Therefore, interfacial reaction between the matrix and the reinforcement phases is prevented. On the other hand, more uniform distribution of the reinforcing particles can be achieved using this technique $[17,18]$. Another advantage of powder metallurgy technique is its ability to manufacture near net shape product at low cost.

The present work aims to study the effectiveness of the complex $\mathrm{Al}_{3} \mathrm{Ca}_{8}$ intermetallic particle as reinforcement in novel $\mathrm{Mg}-7.6 \% \mathrm{Al}$ alloy matrix composite. The emphasis has been given to study the effect of volume fraction of the reinforcement on the microstructure and mechanical properties of the composites.

\section{Experimental}

$\mathrm{Mg}-7.6 \% \mathrm{Al}$ (in mass fraction) alloy matrix was prepared by mechanical alloying of the elemental powder of $\mathrm{Al}$ and Mg using a Retsch PM400 planetary ball mill with hardened steel balls and vials. The powders were milled for $200 \mathrm{~h}$ with a ball-to-powder mass ratio (BPR) of 10:1 and at rotational velocity of $150 \mathrm{r} / \mathrm{min}$. The reinforcement was prepared by crushing of pre-alloyed $\mathrm{Al}_{35} \mathrm{Ca}_{65}$ ingots (prepared by arc melting techniques) followed by $200 \mathrm{~h}$ milling in a separate vial. Handling of samples was carried out in a glove box under purified argon atmosphere $\left(\mathrm{O}_{2}\right.$ and $\mathrm{H}_{2} \mathrm{O}$ volume fraction $\left.<1 \times 10^{-7}\right)$. In order to produce $\mathrm{Mg}$ - based MMCs reinforced with $\mathrm{Al}-\mathrm{Ca}$ intermetallic particles, the $\mathrm{Mg}-7.4 \% \mathrm{Al}$ alloy powder was mechanically mixed in the planetary ball mill with 20,40 , and 60 vol\% of $\mathrm{Al}-\mathrm{Ca}$ intermetallic powder. The composite powders were consolidated by hot pressing at $673 \mathrm{~K}$ and $400 \mathrm{MPa}$. Structural characterization was performed by $\mathrm{X}$-ray diffraction (XRD) using a Philips PW 1050 diffractometer $\left(\mathrm{Co} K_{\alpha}\right.$ radiation, $\lambda=0.17889 \mathrm{~nm}$ ) and by scanning electron microscopy (SEM) using a Gemini 1530 microscope. The Rietveld method was applied for the profile-fitting structure refinement using the WinPlotR software package [19]. The thermal stability was investigated by differential scanning calorimetry (DSC) with a Perkin-Elmer DSC7 calorimeter at heating rate of $20 \mathrm{~K} / \mathrm{min}$ under a continuous flow of purified argon. The density of the hot pressed samples was measured using Archimedes principle. Cylinders having a length/diameter ratio of $2.0(6 \mathrm{~mm}$ of length and $3 \mathrm{~mm}$ of diameter) were prepared from the hot consolidated samples for compression testing in accordance with ASTM standard [20]. The specimens were tested at room temperature using universal testing machine (Instron model 8562) under quasistatic loading (strain rate $\sim 1 \times 10^{-4} \mathrm{~s}^{-1}$ ).

\section{Results and Discussion}

Figure 1a shows the XRD patterns of the as milled and annealed reinforcement and the consolidated composites with different volume fractions of reinforcement. XRD pattern of the as milled reinforcement powder clearly reveals broad peaks of $\mathrm{Al}_{14} \mathrm{Ca}_{13}$ phase and small peaks of $\mathrm{CaO}$, which could be due to oxidation of highly reactive $\mathrm{Ca}$ during handling and sample preparation. The significant peak broadening could be attributed to the reduced crystallite size in nanometer regime. Nanocrystalline phase of the pattern was confirmed by Rietveld structure refinement, which reveals a crystallite size of about $10 \mathrm{~nm}$. Thermal stability of the milled reinforcement powder was also
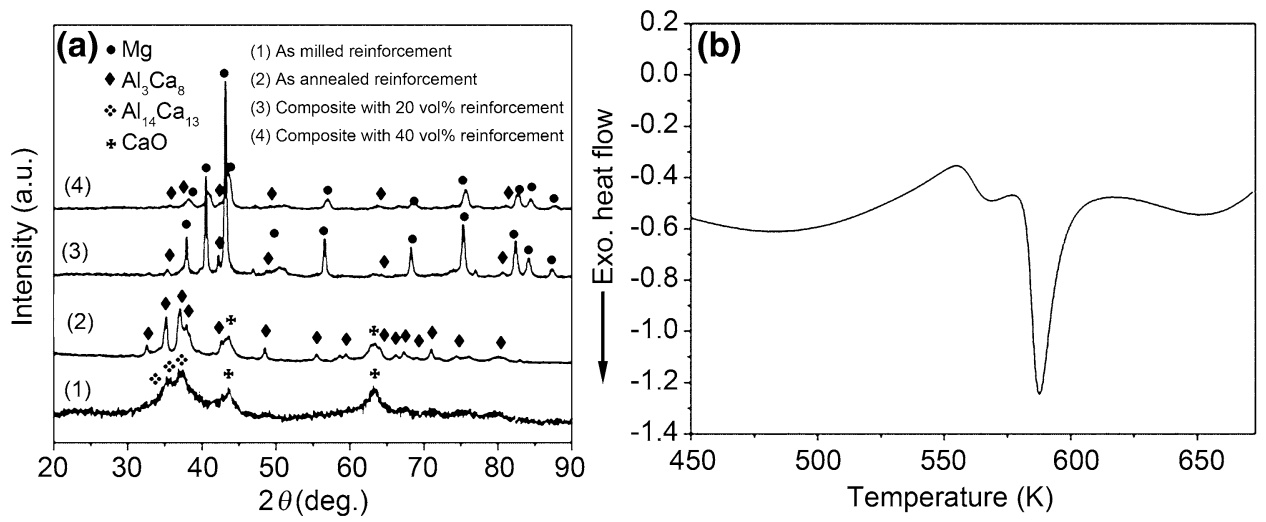

Fig. 1 a XRD patterns for the as milled and annealed reinforcement and composites with 20 and 40 vol\% of $\mathrm{Al}_{35} \mathrm{Ca}_{65}$ powder; $\mathbf{b} \mathrm{DSC}$ curve of the $200 \mathrm{~h}$ milled reinforcement powders (heating rate is $20 \mathrm{~K} / \mathrm{min}$ ) 


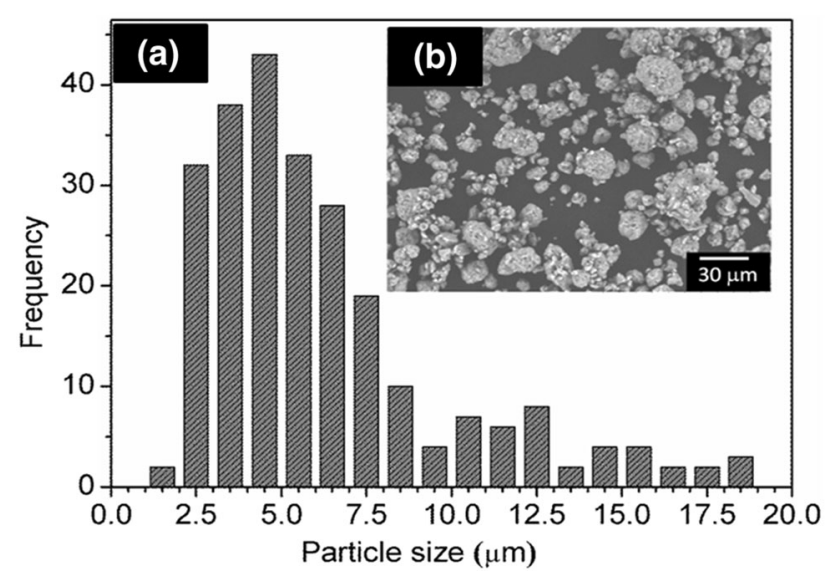

Fig. 2 a Particle size distribution of $200 \mathrm{~h}$ milled $\mathrm{Al}_{35} \mathrm{Ca}_{65}$ powders; b corresponding SEM micrograph of the powder

checked by annealing the powder up to $673 \mathrm{~K}$ in the argon atmosphere at $20 \mathrm{~K} / \mathrm{min}$ using DSC apparatus, and the isochronal DSC curve of the same is shown in Fig. 1b. The DSC curve consists of a broad exotherm between 470 and $550 \mathrm{~K}$ followed by a small exotherm starting at about $560 \mathrm{~K}$ and by a sharp exotherm in the temperature range between 580, and $610 \mathrm{~K}$. Finally, an additional broad exothermic signal occurs at temperature above $620 \mathrm{~K}$. Combined analysis of XRD and DSC result of the annealed powder shows that the $\mathrm{Al}_{14} \mathrm{Ca}_{13}$ phase transforms to $\mathrm{Al}_{3} \mathrm{Ca}_{8}$ phase at $586 \mathrm{~K}$. The heat released for this phase transformation corresponding to the sharp DSC peak at $586 \mathrm{~K}$ is estimated to $9.6 \mathrm{~kJ} / \mathrm{mol}$ ). This value of heat release is remarkably close to that calculated by Islam et al. [21] for same phase transformation $(10.4 \mathrm{~kJ} / \mathrm{mol})$.

Figure 1a also shows the XRD patterns of the consolidated composite with 20 and $40 \mathrm{vol} \%$ reinforcements. They reveal sharp crystalline peaks of pure Mg. Pattern corresponding to the composite containing $40 \mathrm{vol} \%$ reinforcement shows higher intensity of intermetallic phases as compared to the pattern of the composite containing 20 vol\% reinforcement due to higher volume fraction of the intermetallics. The detection of the only three phases in XRD pattern of the composite shows that no reaction had occurred in the present consolidation conditions (hot pressing $673 \mathrm{~K}$ and $400 \mathrm{MPa}$ ).

Figure 2a shows the particle size distribution of the $200 \mathrm{~h}$ milled $\mathrm{Al}_{35} \mathrm{Ca}_{65}$ powders. Clearly indicates that the particle size ranges between 2 and $18 \mu \mathrm{m}$ with mean particle size of about $7 \mu \mathrm{m}$. Figure $2 \mathrm{~b}$ shows the SEM micrograph of the $200 \mathrm{~h}$ milled $\mathrm{Al}_{35} \mathrm{Ca}_{65}$ powders. This mostly consists of round-shaped fine particles along with agglomerated coarse particles.

Figure 3 shows the SEM micrographs of the hot consolidated samples taken from the cross-section of the $\mathrm{Mg}-$ $7.4 \% \mathrm{Al}$ alloy and the composites reinforced by 20,40 , and $60 \mathrm{vol} \% \mathrm{Al}_{3} \mathrm{Ca}_{8}$ particles. The micrographs of the composites reveal the reinforcing $\mathrm{Al}_{3} \mathrm{Ca}_{8}$ particles (white regions), which tend to agglomerate around the matrix
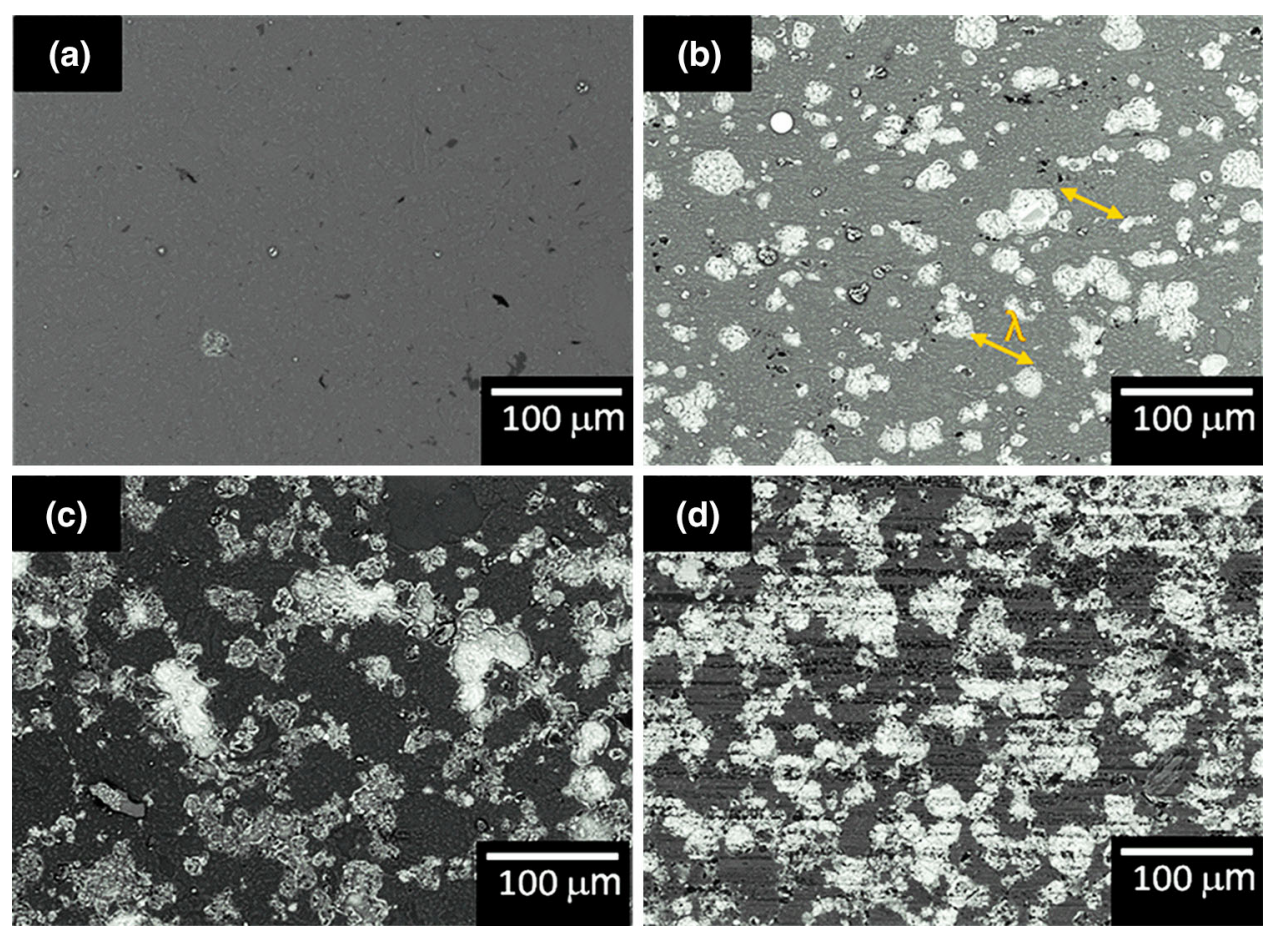

Fig. 3 SEM micrographs for the consolidated $\mathrm{Mg}-7.4 \% \mathrm{Al}$ alloy a, consolidated composites reinforced with $20 \mathrm{vol} \% \mathrm{~b}, 40 \mathrm{vol} \% \mathbf{c}, 60 \mathrm{vol} \%$ d $\mathrm{Al}_{3} \mathrm{Ca}_{8}$ particles 


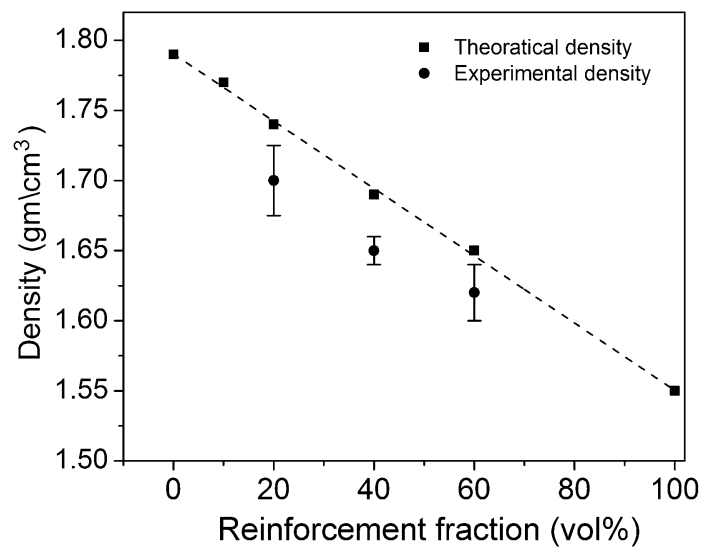

Fig. 4 Experimental (square) and theoretical (circle) densities of the consolidated samples as a function of the volume fraction of $\mathrm{Al}_{3} \mathrm{Ca}_{8}$ reinforcement

particles (dark regions) forming a cell network throughout the sample. As the volume fraction of the reinforcement increases the particles tend to agglomerate forming clusters and further increment in the reinforcement fraction to 40 and $60 \mathrm{vol} \%$, the cluster regions become more and more interconnected. However, the overall distribution of the reinforcement in the matrix remains fairly uniform. The microstructure of the composite does not show any porosity, corroborating the high density of the samples. The density linearly decreases with increasing amount of reinforcement from about $1.79 \mathrm{~g} / \mathrm{cm}^{3}$ for unreinforced matrix to $1.65 \mathrm{~g} / \mathrm{cm}^{3}$ for the reinforced composite with $60 \mathrm{vol} \%$ reinforcement, which corresponds to a reduction of about $8 \%$ with respect to the unreinforced matrix (Fig. 4). The decrease in density of the composite shows usual behavior, as the reinforcement being light in comparison with the matrix.

The room temperature compressive stress-strain curves under quasistatic loading of the composites and

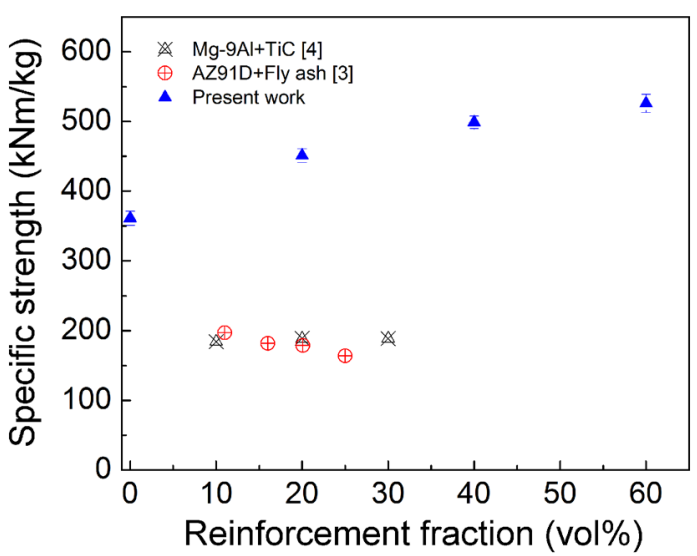

Fig. 6 Specific strength of the composites as a function of the fraction of intermetallic reinforcement. For comparison purposes, the values for Mg-based MMCs reinforced with fly ash [3] and TiC [4] evaluated by compression tests are also reported

unreinforced $\mathrm{Mg}-7.4 \% \mathrm{Al}$ matrix are shown in Fig. 5a, and the corresponding mechanical data are summarized in Fig. 5b. The addition of the nanostructured reinforcement remarkably improves the mechanical properties of the $\mathrm{Mg}-$ 7.4\% Al alloy matrix. The compressive strength (the maximum compressive stress which the material is capable of sustaining [22]) increases from $683 \mathrm{MPa}$ for unreinforced matrix to 767,823 , and $852 \mathrm{MPa}$ for the composites with 20, 40, and 60 vol\% reinforcement, respectively. These results indicate that the addition of the nanostructured reinforcement leads to composite having compressive strengths exceeding that of unreinforced matrix (to the order of $13-24 \%$ ), while retaining appreciable plastic deformation. This increase in compressive strength could be attributed to well-known factors (pertaining to reinforcement) such as: (1) the dislocation strengthening in the matrix, which is related to the nucleation of additional dislocations in the matrix due to the introduction of the
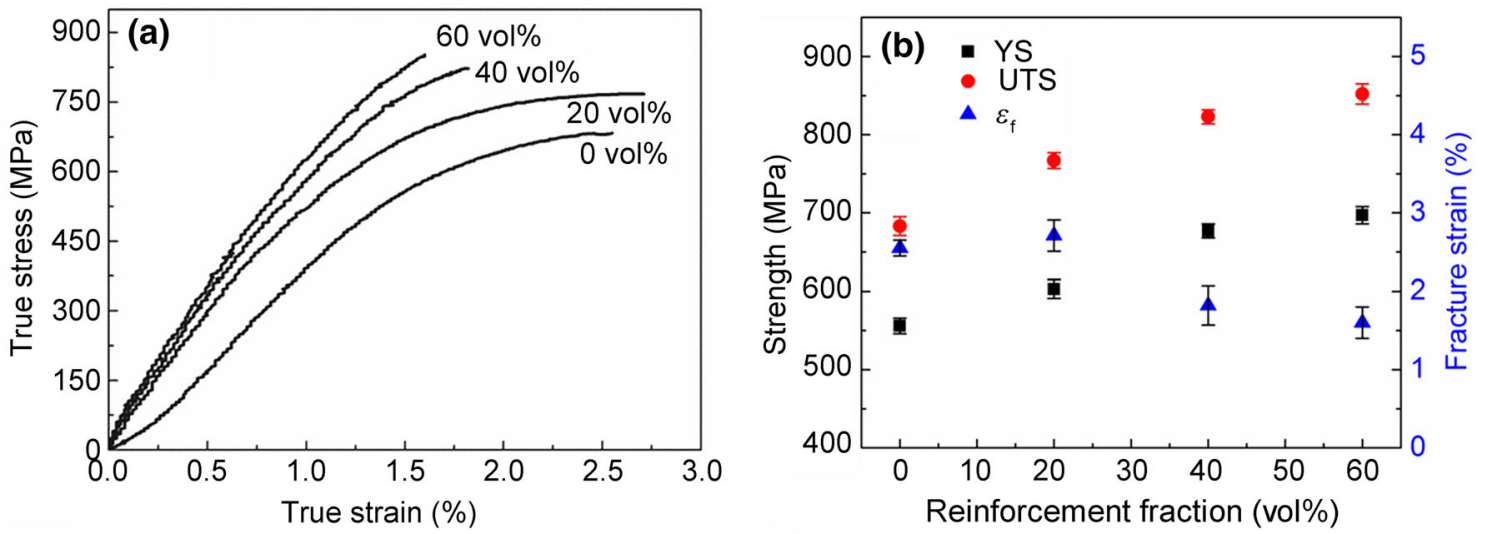

Fig. 5 a Room temperature compression true stress-true strain curves for the consolidated unreinforced $\mathrm{Mg}-7.4 \mathrm{Al}$ matrix and composites with 20 vol.\% $(\mathrm{V}=20), 40$ vol.\% $(\mathrm{V}=40)$ and 60 vol.\% $(\mathrm{V}=60)$ of nanostructured $\mathrm{Al}_{3} \mathrm{Ca}_{8}$ particles, b corresponding data of mechanical properties 
reinforcement [23, 24], (2) Orowan strengthening mechanism [25], and (3) load transfer from the matrix to reinforcement [24].

The addition of low-density $\mathrm{Al}_{3} \mathrm{Ca}_{8}$ particles decreases the density of the composites below that of unreinforced matrix (Fig. 4). Figure 6 indicates the variation of specific strength (tensile or compressive strength divided by the density), as a function of volume fraction of the reinforcement. It is very clearly indicated in this figure that the specific strength sharply increases from about $361 \mathrm{kN} \mathrm{m} /$ $\mathrm{kg}$ for unreinforced matrix to $450 \mathrm{kN} \mathrm{m} / \mathrm{kg}$ for the composite with 20 vol\% $\mathrm{Al}_{3} \mathrm{Ca}_{8}$ reinforcement and $498 \mathrm{kN} \mathrm{m} /$ $\mathrm{kg}$ for the composite with $40 \mathrm{vol} \% \mathrm{Al}_{3} \mathrm{Ca}_{8}$ reinforcement. The specific strength further increases to about $526 \mathrm{kN} \mathrm{m} /$ $\mathrm{kg}$ for the composite with $60 \mathrm{vol}$ of $\mathrm{Al}_{3} \mathrm{Ca}_{8}$ reinforcement. These values of specific strengths are higher than those reported for AZ92D/Fly ash [3], and AZ92D/TiC [4] composites evaluated by compression tests (Fig. 6). Since a high specific strength is one of the most important aspects of lightweight materials, the composites reinforced with intermetallic particles in the present case could be a better alternative to conventional ceramic-reinforced composites.

\section{Conclusions}

$\mathrm{Mg}-7.4 \%$ Al matrix reinforced with different volume fractions of nanocrystalline $\mathrm{Al}_{3} \mathrm{Ca}_{8}$ intermetallic particles has been produced by powder metallurgy, and their mechanical properties have been investigated under compressive loading. The results reveal encouraging room temperature mechanical properties with respect to the unreinforced $\mathrm{Mg}-7.4 \% \mathrm{Al}$ matrix. Yield and compressive strength have increased from 556 to $683 \mathrm{MPa}$ for unreinforced alloy matrix to about 677 and $823 \mathrm{MPa}$ for the composite reinforced with $40 \mathrm{vol} \% \mathrm{Al}_{3} \mathrm{Ca}_{8}$ intermetallic particles, respectively, while retaining appreciable plastic deformation. Furthermore, the addition of low-density $\mathrm{Al}_{3} \mathrm{Ca}_{8}$ intermetallic phase decreased the density of the composite and significantly increased the specific strength of the composites.

Acknowledgments The authors are thankful to DAAD for their financial support to carry out this work.

\section{References}

[1] X.J. Wang, K. Wu, W.X. Huang, H.F. Zhang, M.Y. Zheng, D.L. Peng, Compos. Sci. Technol. 67, 2253 (2007)

[2] Y.H. Lim, S.C. Lim, M. Gupta, J. Wear 225, 629 (2003)

[3] Z. Huang, S. Yu, M. Li, Trans. Nonferrous Met. Soc. China 20, 458 (2010)

[4] A. Munitz, I. Jo, J. Nuechterlein, W. Garrett, J.J. Moore, M.J. Kaufman, Int. J. Mater. Sci. 2, 15 (2012)

[5] S. Jayalakshmi, S.V. Kailas, S. Seshan, Compos. A 33, 1135 (2002)

[6] L.Q. Chen, Q. Dong, M.J. Zhao, J. Bi, N. Kanetake, Mater. Sci. Eng. A 408, 125 (2005)

[7] M.Y. Zheng, K. Wu, S. Kamado, Y. Kojima, Mater. Sci. Eng. A 48, 67 (2003)

[8] J.M. Lee, S.B. Kang, T. Sato, H. Tezuka, A. Kamio, Mater. Sci. Eng. A 343, 199 (2003)

[9] M.A. Muñoz-Morris, J.I. Rexach, M. Lieblich, Intermetallics 13, 141 (2005)

[10] J.M. Torralba, F. Velasco, C.E. Costa, I. Vergara, D. Cáceres, Compos. A 33, 427 (2002)

[11] F. Velasco, W.M. Lima, N. Antón, J. Abenójar, J.M. Torralba, Tribol. Int. 36, 547 (2003)

[12] B. Huang, J.D. Corbett, Inorg. Chem. 37, 5827 (1998)

[13] J. Zhu, Y. Miao, J.T. Gu, Acta Mater. 45, 1989 (1997)

[14] K. Matsuyama, Sci. Rep. Tohoku Univ. 17, 783 (1928)

[15] S.H. Wang, Nanocrystalline Metals and Alloys: Processing, Microstructure, Mechanical Properties and Applications (Wood head Publishing Limited, Cambridge, 2011)

[16] K.U. Kainer, Metal Matrix Composites Custom-made Materials for Automotive and Aerospace Engineering (Wiley-VCH, Weinheim, 2006)

[17] J.B. Fogagnolo, F. Velasco, M.H. Robert, J.M. Torralba, Mater. Sci. Eng. A 342, 131 (2003)

[18] A.K. Chaubey, S. Scudino, N.K. Mukhopadhyay, M.S. Khoshkhoo, B.K. Mishra, J. Eckert, J. Alloys Compd. 536, 134 (2012)

[19] T. Roisnel, J. Rodríguez-Carvajal, Mater. Sci. Forum 378-381, $118(2001)$

[20] ASTM E9-89a, Standard Test Methods for Compression Testing of Metallic Materials at Room Temperature, (ASTM International, West Conshohocken, 2000), pp. 1-9

[21] F. Islam, M. Medraj, Can. Metall. Q. 44, 523 (2004)

[22] ASTM E6-03, Standard Terminology Relating to Methods of Mechanical Testing (ASTM International, West Conshohocken, 2003), pp. 1-11

[23] S.F. Hassan, M.J. Gupta, Mater. Sci. 41, 2229 (2006)

[24] N. Shi, B. Wilner, R.J. Arsenault, Acta Metall. Mater. 40, 2841 (1992)

[25] Z. Szaraz, Z. Trojanova, M. Cabbibo, E. Evangelist, Mater. Sci. Eng. A 462, 225 (2007) 